\title{
The Role of Transport and Population Components in Change in Accessibility: the Influence of the Distance Decay Parameter
}

\author{
Marcin Stępniak $^{1}$ (D) Piotr Rosik $^{1}$
}

Published online: 21 December 2017

(C) The Author(s) 2017. This article is an open access publication

\begin{abstract}
Investment in transport infrastructure is the main factor responsible for decreasing origin-destination travel times, which are then implemented into a potential accessibility measure. This measure uses population size as a proxy for a destination's attractiveness. Thus, changes in population distribution as well as the development of the transport infrastructure are mutually responsible for changes in accessibility. The potential accessibility measure is applied to assess change in accessibility in Poland over a twenty year period of time (1995-2015). During this time Poland has experienced a significant change in population distribution. At the same time, accession to the European Union provided an opportunity to use the structural funds and has resulted in an unprecedented development of the transport infrastructure, in particular the road network. The coexistence of both phenomena provides perfect conditions to investigate the complex interrelationship of both components of accessibility, namely transport and land-use. This leads towards a change in the level of accessibility and its spatial pattern, resulting in a transformation of the level of territorial cohesion. However, the selection of the particular impedance parameters greatly influences the importance assigned to an element of infrastructure or a component of population accessibility. Thus, several impedance functions are applied in order to capture their influence on the balance between the infrastructure and population components of accessibility change.
\end{abstract}

Keywords Potential accessibility · Transport infrastructure development · Distance decay $\cdot$ Territorial cohesion $\cdot$ Poland

Electronic supplementary material The online version of this article (https://doi.org/10.1007/s11067-0179376-8) contains supplementary material, which is available to authorized users.

Marcin Stępniak

stepniak@twarda.pan.pl

1 Institute of Geography an Spatial Organization, Polish Academy of Science, Warsaw, Poland 


\section{Introduction}

One of the most visible outcomes of transport infrastructure development is an increase in accessibility, facilitating people's ability to reach desired destinations. Nevertheless, transport infrastructure constitutes only one of the two main components of accessibility that may influence its level and spatial pattern. The land use component, which includes the amount and spatial distribution of opportunities and the demand for those opportunities (Geurs and van Wee 2004), is responsible for shaping the spatial pattern of travel demand, and in so doing, it may have a decisive impact on the measurement of accessibility. The role of the land use component is usually under-investigated in the case of those accessibility studies that focus on the evaluation of transport infrastructure development. These studies, which aim to evaluate a net effect of transport infrastructure development (e.g. Stelder 2013; Salas-Olmedo et al. 2014; Rosik et al. 2015), usually apply fixed values in order to describe land use pattern. This approach is straightforward for an assessment of change in accessibility resulting from a particular investment or set of investments (e.g. road network development programmes). Nevertheless, the mid or long term monitoring of accessibility should consider that infrastructure development does not act in a vacuum but in specific external conditions. Any significant change of these external conditions, like e.g. the depopulation of peripheral regions, the rise or decline of particular urban areas etc., creates new settings and affects both the results of accessibility measurement and the way in which we interpret these results.

This is especially the case when an accessibility study focuses on the impact of developments of the transport network on territorial cohesion. Unequal accessibility is not necessarily problematic (van Wee and Geurs 2011), as space, "by its very nature is divided into centre and periphery" (Martens et al. 2012: 687). Moreover, a delineation of peripheral, less accessible areas, such as their level of peripherality (Spiekermann and Neubauer 2002), might evolve over a time. In consequence, the level of territorial cohesion also changes, regardless of the actual development of the transport infrastructure. Thus, our intention is to overcome the existing obstacles in contemporary accessibility studies, by separating out accessibility changes that result from the development of transport infrastructure from those caused by the changes in land use. The relatively long period of time investigated (20 years) consists of a period of stagnation in transport investment (1995-2005) followed by a significant acceleration in the development of the road network (2005-2015). It facilitates the provision of meaningful conclusions regarding the role of a given component, irrespective of external conditions. These include, apart from infrastructure-related, demographic change, the changes in population distribution in Poland (e.g. depopulation, shrinking small and medium-size towns, suburbanisation etc.).

The aim of the paper is to determine the role of given components, namely population and infrastructure, in change in accessibility and territorial cohesion in Poland during the last two decades (1995-2015). During the investigated period of time, and in the second decade in particular, Poland has experienced a significant growth of road development, comparable to what one could observed in France (Fayard et al. 2012) or Switzerland (Erath et al. 2009) in the mid of the twentieth century, or in Spain since 1980s (Condeço-Melhorado et al. 2017). In order to do this we use the potential accessibility model, which is widely used to evaluate effectiveness and the 
equity impact of transport infrastructure developments in a mid- or long-term period of time i.e. a decade or more (Vickerman et al. 1999; Holl 2007; Condeço-Melhorado et al. 2011b; Levinson et al. 2012; Rosik and Stępniak 2015; Rosik et al. 2015; SalasOlmedo et al. 2015). As the potential accessibility model is sensitive to the parameters of the distance decay function (Haynes et al. 2003), the selection of particular parameters for the model potentially influences the balance between the infrastructure and population components of accessibility change and its impact on the level of territorial cohesion. Thus, this study contributes to the existing body of accessibility literature by taking into consideration different gradients of the distance decay function that enable the researcher to obtain results independent of impedance parameters. The paper is organised as follows. The next section starts by presenting some key concepts relating to the evaluation of accessibility change with special attention given to the role of land use change and infrastructure development. A short description of the study area, focusing on changes in the population distribution (the land use component) and road network development (the transport component) is then presented. The main results are presented in Section 4, followed by general conclusions and final remarks.

\section{Accessibility: Components, Dynamics and Evaluation}

Accessibility is a commonly used term in transport and urban planning and transport geography (Geurs and van Wee 2004; Reggiani and Martín 2011). Change in accessibility level is associated with an increase of productivity (Aschauer 1989) and it influences on retail prices (Jiménez and Perdiguero 2011) or decisions about location of firms (Holl 2004; Holl and Mariotti 2017). In general terms, accessibility is understood as the potential of opportunities for interaction (Hansen, 1959), however one can find an on-going debate on its precise and coherent definition in literature dedicated to this topic. Regardless of these uncertainties, most authors agree on the existence of certain components that are integral elements of accessibility. Two main components arise from the existing body of literature. The transport component (this term can also be termed resistance, impedance, deterrence or friction) reflects the ease (or difficulty) of travelling between the origin and destination and is determined by the nature and quality of services provided by the transport system (Handy and Niemeier 1997). Geurs and Ritsema van Eck (2001) indicate that the transport component can be characterised by the supply of infrastructure, its location and its characteristics. Thus, transport infrastructure development may be treated as an impact of the transport component on the change in the accessibility level and its spatial distribution. The land use component describes the spatial distribution of the destinations available and the spatial distribution of the demand for activities and the characteristics of both demand and supply, including the relationship between them in space (Geurs and Ritsema van Eck 2001). Population change, including changes of the spatial distribution of the population and its total number, mirrors a land use component of accessibility.

The spatial differentiation of the dominance of the transport or population components is a result of interplay between them. The transport component in the accessibility studies might be exemplified by development of infrastructure (e.g. CondeçoMelhorado and Christidis 2017), congestion (e.g. Moya-Gómez et al. 2017; Moya- 
Gómez and García-Palomares 2017) or road pricing (e.g. Condeço-Melhorado et al. 2011a, b; Solé-Ribalta et al. 2017). Thus, the impact of the transport component might be positive (e.g. due to road network development) as well as negative (e.g. by increased congestion or rise of road pricing). However in the presented study we limit our scope of interest to the first issue. In such approach, the transport component affects the accessibility level in a positive way, as it increases accessibility through the development of infrastructure. The impact of the population component might be either positive, if regional population rises, or negative, if population decreases. Thus, the land-use and transport components are associated multiplicatively (Spiekermann and Neubauer 2002). The definition of accessibility is built on the assumption that the attractiveness of a destination (reflecting the land-use component) increases as the distance, travel time or cost between origin and destination decreases (transport component). If the population represents the activity function and time is chosen as an element in the impedance function, the link between components can be represented by the formula:

$$
A_{i}=\sum_{j} f_{1}\left(P O P_{j}\right) f_{2}\left(t_{i j}\right),
$$

where $A_{i}$ is the accessibility of transport zone $i$, the land-use component is represented by the activity function $f_{l}\left(P O P_{j}\right)$, the population accessible in the transport zone $j$ $\left(P O P_{j}\right)$ is a proxy of destination attractiveness, the transport component is represented by the impedance function $f_{2}\left(t_{i j}\right)$ and $t_{i j}$ is the travel time between transport zones $i$ and $j$. Additionally, the value of $A_{i}$ is enlarged by a so-called 'self-potential', i.e. the potential produced by the unit itself.

The above general formula is commonly used for the evaluation of changes in the accessibility level however the evaluation of mid- or long-term changes in accessibility at national level is rather rare, with a few notable exceptions (see Table 1). The formula's two relatively easily separable parts provide an effective tool for the evaluation of accessibility dynamics and the assessment of the role of either of its two components. Two of the main approaches may be defined in the examples listed. The first of these focuses on the net effect of accessibility change and results directly from transport infrastructure development. As a result, only a change in the transport component is taken into consideration, which is exemplified by the reduction of travel time between the affected pairs of origin-destination nodes. In that case two (or more) scenarios are investigated, the scenarios before and after completion of the (set of) investment(s) are compared and then the land use component is treated as constant (the ceteris paribus approach). Hereinafter we will call this case the infrastructure variant. The second approach, a fully dynamic one (hereinafter referred to as the dynamic variant), recalculates the accessibility level for each variant using the actual state of both the land use and infrastructure components at given point in time. The third option assumes that the state of the transport infrastructure remains constant and enables the separation of the impact of the land use component in the total change of accessibility (population variant). This last is hardly ever used in accessibility studies as it focuses on population redistribution in space and it deals with population studies rather than accessibility and transport issues, however it may also be considered when evaluating e.g. new land-use polices (Geurs and Ritsema van Eck 2001; Xie and Levinson 2007). 


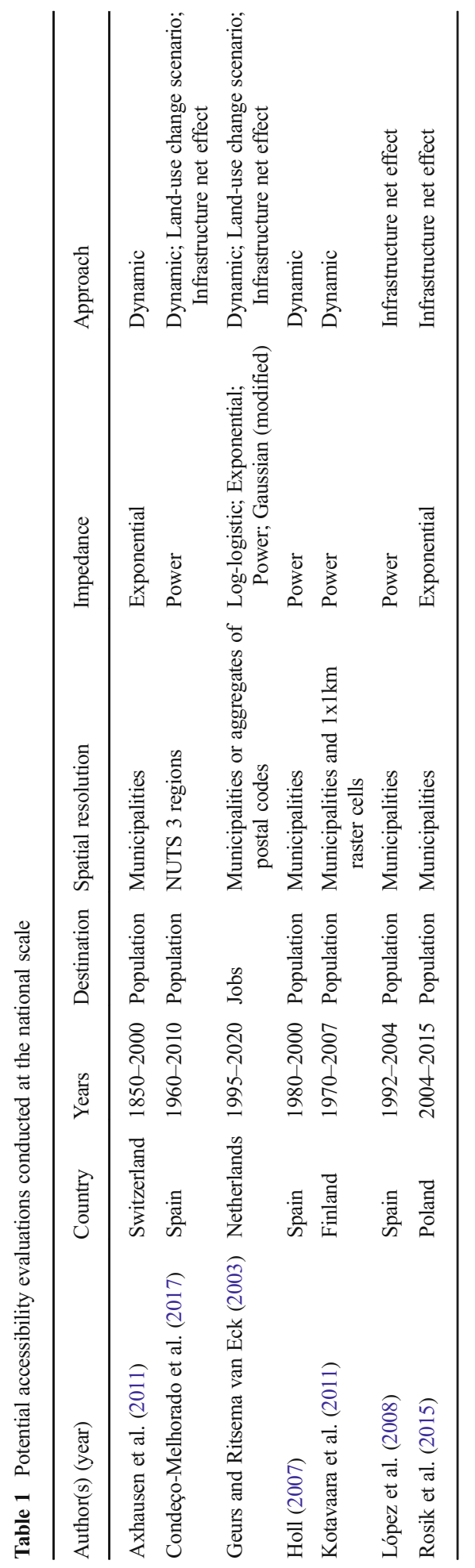


Thus, we share a common point of departure with previous studies conducted by Geurs and Ritsema van Eck (2003) and Condeço-Melhorado et al. (2017). We separate infrastructure and land use components in order to evaluate their contribution to the overall accessibility change. However, our focus is not limited to the accessibility improvements and the role of the two accessibility components (i.e. transport and land use). Apart from that, our study employs all three approaches in order to investigate also the impact of the overall change in accessibility on the level of territorial cohesion. Finally, our previous attempt (Rosik and Stępniak 2015) suggests contradictory results to the cited studies, which pointed out the dominance of land use over the infrastructure component. Thus, we decide to test how and to what extent, the change of gradients of the distance decay function influences our conclusions.

In all three cases we apply a general formula for the potential accessibility indicator, with slight modifications that enable us to implement a ceteris paribus approach in order to investigate the role of the population (land use) and transport components. In the dynamic variant we change both the population (i.e. $\left.f\left(P O P_{j}\right)\right)$ as well as the transport (i.e. $\left.f\left(t_{i j}\right)\right)$ components of the potential accessibility measure recalculating them for each of the years to be investigated within our study period (1995-2015). The infrastructure scenario uses the population component as a constant (i.e. values for the base year of 1995), while the population scenario implements constant travel times, each being based on the state of the road network at the start of our study period. In order to evaluate the role of a given component $\left(R_{c}\right)$ we implement the following formula:

$$
R_{c}=\left\{\begin{array}{l}
1-\frac{\left|\Delta \mathrm{A}_{D}-\Delta \mathrm{A}_{I}\right|}{\left|\Delta \mathrm{A}_{D}-\Delta \mathrm{A}_{P}\right|} \text { for }\left|\Delta \mathrm{A}_{I}\right|>\left|\Delta \mathrm{A}_{P}\right| \\
0 \text { for }\left|\Delta \mathrm{A}_{I}\right|=\left|\Delta \mathrm{A}_{P}\right| \\
\frac{\left|\Delta \mathrm{A}_{D}-\Delta \mathrm{A}_{P}\right|}{\left|\Delta \mathrm{A}_{D}-\Delta \mathrm{A}_{I}\right|}-1 \text { for }\left|\Delta \mathrm{A}_{I}\right|<\left|\Delta \mathrm{A}_{P}\right|
\end{array},\right.
$$

where $\Delta \mathrm{A}_{\mathrm{D}}$ stands for accessibility absolute change according to the dynamic scenario and $\Delta \mathrm{A}_{\mathrm{P}}$ and $\Delta \mathrm{A}_{\mathrm{I}}$ mean the accessibility absolute changes resulting from the population (infrastructure constant) and infrastructure (population constant) components respectively. Values of $R_{c}$ range from -1 - indicating the dependency of accessibility change on the population component, to +1 (dominance of the infrastructure component). Values close to zero show that the impact of both components is balanced, with $R_{c}$ equal to zero referring to (hypothetical) complete equality.

Potential accessibility analysis is sensitive to what is known as accessibility dimensions. Spiekermann and Neubauer (2002) identified a number of accessibility dimensions: origins, destinations, constraints and barriers, types of transport and modes, spatial scale, equity, dynamics and, last but not least, spatial impedance. In this study, we aim to make our results independent of impedance parameters. As Östh et al. (2014) pointed out, a precise estimate of the distance decay function is a decisive factor in the reliable measurement of accessibility. This estimation process should include both the selection of the particular type of function and the estimation of its parameters. Table 1 reflects the main divisions in studies which apply potential accessibility measures at the national level over a certain period of time as far as the selection of power or 
exponential functions is concerned. The comparison between the two might be found elsewhere (e.g. Kwan 1998; Reggiani et al. 2011; Östh et al. 2014), in this study we decide to focus our attention on negative exponential functions.

Thus, the manipulation of the form of the impedance function is made by the $\beta$ parameter, which reflects the duration of travel and the level of peripherality. The more locally we look at regional or local differences in accessibility, the shorter the trip length and steeper is the distance decay (with higher $\beta$ values). Östh et al. (2014) promote a 'half-life approach', recalling the radioactive isotope Carbon-14 which is commonly used for dating organic materials. Translated to the accessibility context, this approach assumes that a typical (median) trip length $(\bar{t})$ for a given purpose should be achieved at the point at which the attractiveness of the destination is reduced by half:

$$
-\beta=\frac{\ln (0.5)}{\bar{t}},
$$

A similar approach was taken by the ESPON TRACC study (Spiekermann et al. 2013). Moreover, the above-mentioned report exemplifies the point that different $\beta$ values may be applied in order to investigate different trip purposes. Further, different $\beta$ values lead to different results, in terms of both the absolute values of accessibility and its spatial pattern (e.g. Stepniak and Rosik 2013). Thus, the outcome of potential accessibility analysis might be biased by the selection of a particular $\beta$ parameter. Finally, in the previous studies one can find a wide range of $\beta$ parameters (for a review consult: Rosik et al. 2015). Our approach includes repetition of accessibility computation for a wide range of $\beta$ parameters in order to illustrate change in accessibility and the role of particular components, including their variation resulting from the selection of the parameters of the distance decay function. Since the 'half-life approach' relates to the value of the $\beta$ parameter with a 'typical' travel time, hereinafter we use short(er) or long(er) trips as an analogy for steep(er)/smooth(er) distance decay, i.e. higher/lower values of the $\beta$ parameter, starting with 5 min half-life and then after each 5 min time span up to one hour and then after each $10 \mathrm{~min}$ up to two hours half-life resulting in 18 simulations for each year of the period analysed (Fig. 1).

Different slopes of the distance decay function influence both the spatial range of spillovers and intra- and inter-regional disparities in levels of accessibility (CondeçoMelhorado et al. 2013). In a given paper, the former is understood to be the positive outcome of investments in a given area that occur in neighbouring regions (Pereira and Roca-Sagalés 2003), however it should be noted that a negative spillovers might occur, e.g. as an effect of high network connectivity between high and under-developed regions (Jiang et al. 2016). Although a negative impact is also possible, e.g. due to the implementation of road pricing schemes (Condeço-Melhorado et al. 2011a), in the study presented here we focus on positive impacts in terms of an increase in accessibility. Unlikely previous attempts, which link spillover effects to the evaluation of a particular investment, e.g. new high speed rail (Ortega et al. 2012) or road segments (Stepniak and Rosik 2013), we use the term "spatial spillover" to explain changes in the accessibility level in a given area that are caused by development of transport infrastructure which extend beyond the limits of neighbouring regions (Yu et al. 2013). 


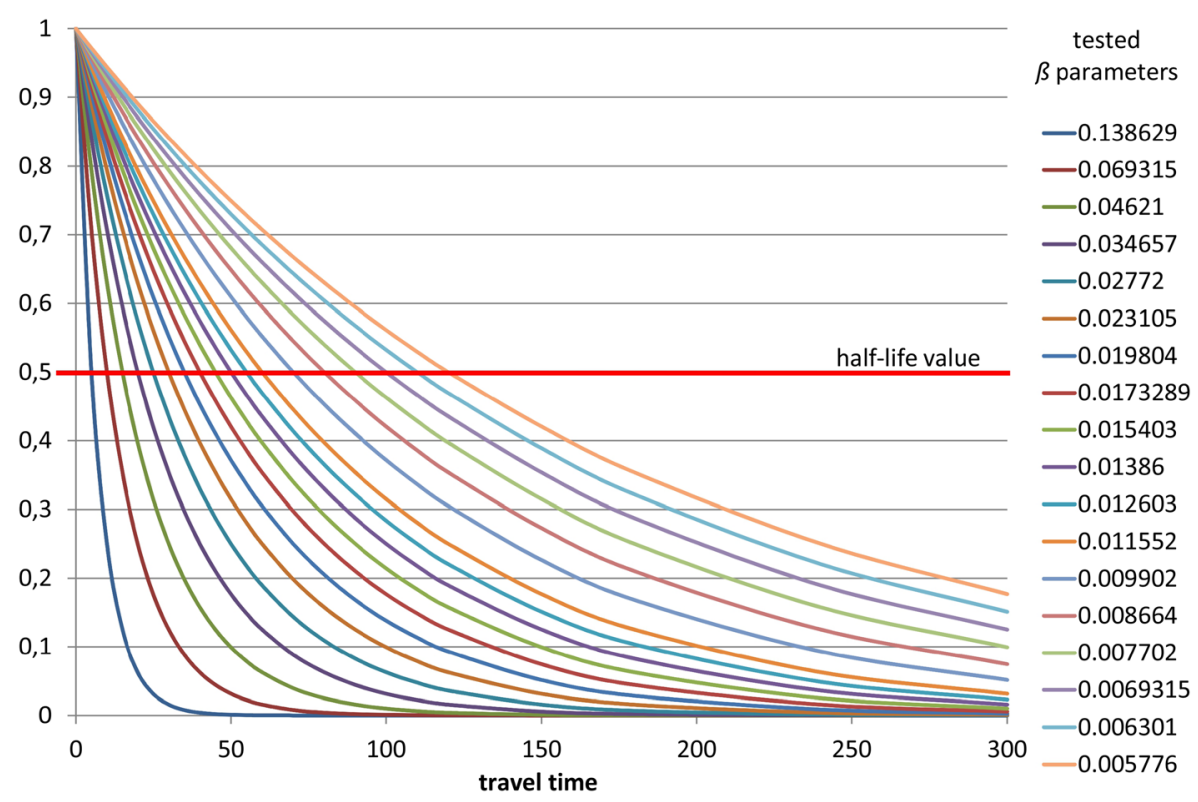

Fig. 1 Gradient of the distance decay values tested and the respective values of $\beta$ parameters

A selection of particular $\beta$ values has an impact on the level of spatial disparities. Following the logic of the European Commission's Third Cohesion Report (CEC 2004), we understand the aim of territorial cohesion to be a need for the avoidance of territorial imbalances. In the Fourth Cohesion Report (CEC 2007), the European Commission directly links the territorial cohesion process with accessibility, underlining the decisive role of efficient and balanced transport infrastructure in the sustainable development of the EU. The calculation of the impact of infrastructure development on the territorial cohesion process is carried out by the use of the potential accessibility dispersion index (Ortega et al. 2012).:

$$
A D=\frac{S D_{A i}}{\frac{\sum A_{i} * P_{i}}{\sum P_{i}}},
$$

where $A_{i}$ stands for the value of potential accessibility in unit $i, S D_{i}$ is its standard deviation and $P_{i}$ is the quantified attractiveness of the destination (in our case equal to population size). The $A D$ index takes higher values to indicate a more polarised accessibility distribution. In this case the sigma divergence process is taking place. The term has been borrowed from neoclassical growth theory where the sigma convergence is defined as the lowering of variance of real per capita income among the countries or regions considered (Barro and Sala-i-Martin 1992). We evaluate changes in the level of territorial cohesion by comparing $\mathrm{AD}$ values obtained for a particular scenario at the national level in a given year (for the spatial distribution of the pro- and anti-cohesion effects see also Stępniak and Rosik 2016).

A consequence of the introduction of the goal of territorial cohesion into transport infrastructure developments is that the evaluation of investments in 
transport infrastructure should be understood as a complex interplay between their efficiency (i.e. greater improvement in accessibility) and equity (i.e. lower regional disparities). The tension between the overall improvement on the one hand and the regional convergence process on the other is seen as a major part of the evaluation of infrastructure investments (Thomopoulos et al. 2009; Geurs et al. 2016). Although reducing equity and promoting efficiency are, at first glance, conflicting goals (Geurs et al. 2016), the introduction of both egalitarian (when everyone has equal accessibility) and utilitarian (maximizing the total accessibility level) approaches is a very desirable policy objective. We propose to evaluate accessibility dynamics and the assessment of the role of transport and population components with an additional in-depth view on the convergence/divergence process by distinguishing four possibilities for representing the interplay between efficiency and equity:

1. A growth in accessibility at the expense of regional polarisation;

2. The simultaneous occurrence of both an increase in overall accessibility and regional convergence;

3. The convergence process at the expense of a decline in overall accessibility;

4. A simultaneous decline in accessibility and regional polarisation.

The four possible scenarios for the two decades being analysed are verified using 18 different decay parameters.

\section{Case Study Area}

\subsection{Population Component}

Following the collapse of the communist system in 1989, Poland has remained, together with Czechia and Slovakia, the most demographically stable of the former USSR-aligned countries in Europe. The population decline resulting from outmigration after joining the EU was counterbalanced by a positive birth rate in the years 2006-2012 as an echo of the second baby boom of the late 70's and early 80's. As a result the population has maintained itself between 38.1 and 38.6 million people over the last two decades and annual variations refer mainly to changes in methodology (Śleszyński 2005). ${ }^{1}$

Regardless of the relative stability of the national population size, a significant change in population was noticed at the local (i.e. municipal) level (Fig. 2). Some areas, mostly in the eastern part of the country, experienced significant depopulation processes (Wiśniewski et al. 2016). Further, strong suburbanisation has led towards urban shrinkage (Zborowski et al. 2012) and rapid growth of suburban areas. Moreover, this process is no longer limited to the largest metropolitan areas, but it likewise affects

\footnotetext{
${ }^{1}$ The official statistics on population in Poland suffer from an underestimation of international migration outflow related to the opening of the labour market in the EU, mainly to the UK and Germany (Fihel et al. 2011), inflow (Kaczmarczyk et al. 2014), and by the partial omission of internal migration (Śleszyński 2011). Bearing in mind its deficiencies, we rely on official statistics in the present paper.
} 


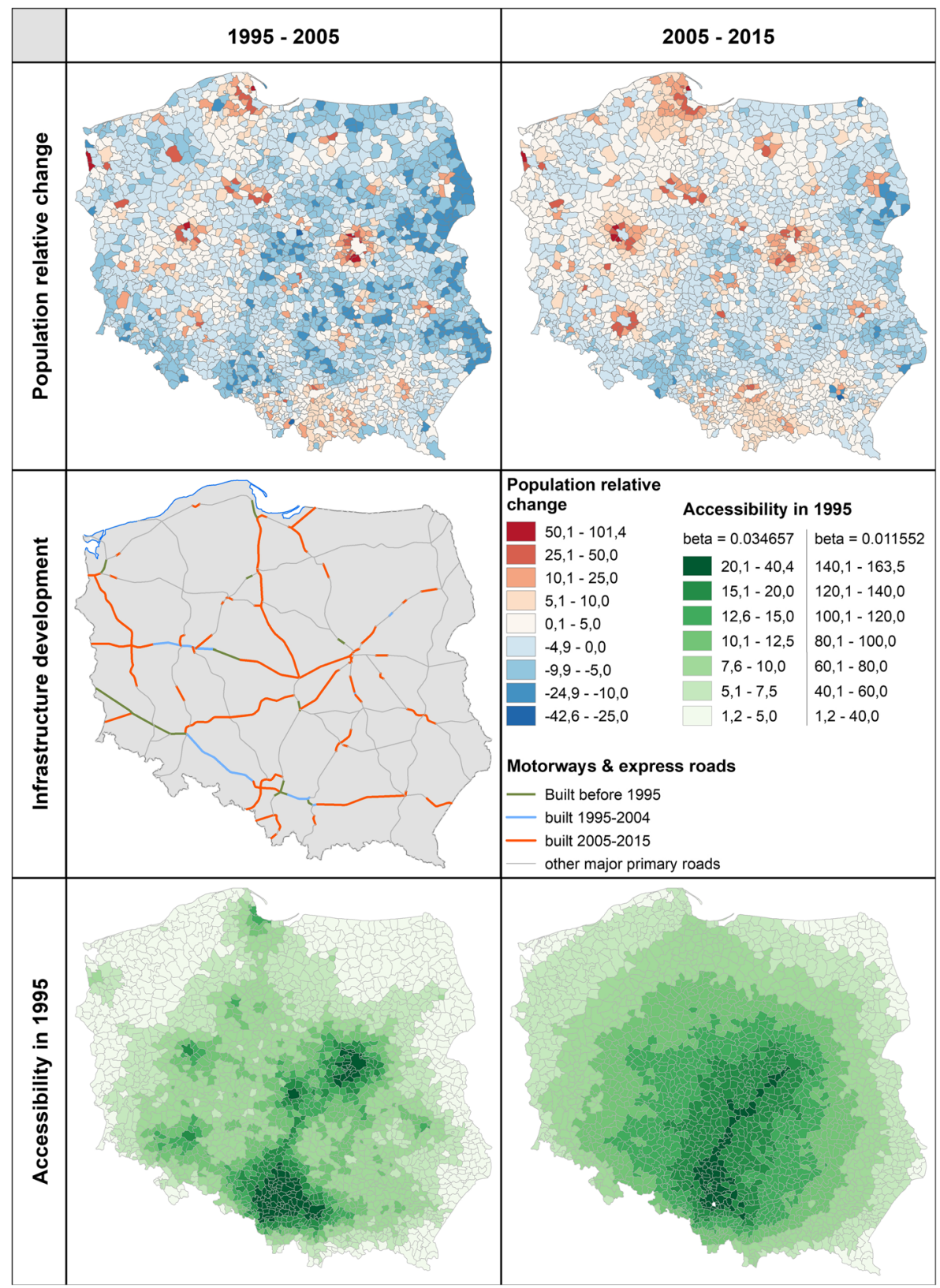

Fig. 2 Population change at the municipal level and development of the road network in Poland (1995-2015)

large and medium-size cities (Śleszyński 2013). Thus, most urban cores (except Warsaw) and rural areas in the East lost population, while suburbs noticed a significant population inflow. 


\subsection{Infrastructure Component}

During the socialist period (1945-1989), the development of the road network in Poland was exclusively the domain of planners, without any actual work taking place on the ground. In consequence, the Polish 'high-speed-road network' in the early 90s was basically non-existent and the road network was merely based on national roads, mostly single carriageway and in very bad physical condition due to long-lasting neglect of infrastructure investments. The only section of motorway that did exist, with a length of (almost) $100 \mathrm{~km}$, was part of the heritage of the German Reich and their Reichsautobahn plan from the 1930s (from Wrocław towards the West). The other motorways totalled about $200 \mathrm{~km}$, divided into several, unconnected and very short segments of road of a few, up to a dozen kilometres, randomly distributed across the country. Due to the severe economic crisis at the beginning of the nineties, and the lack of political decisions the 'continuation' of an inability to undertake transport developments had taken place. Even though there was a $50 \%$ increase in the length of modern roads (i.e. motorways and express-roads, according to Polish nomenclature), during the decade 1995-2004, the network remained fragmented, consisting of separated, relatively short segments (Taylor 2006; Komornicki 2007), with the only exception occurring in the southern part of the country (Fig. 2). The first sign of change took place in 2004 when the Polish Minister of Transport prepared a very ambitious road network development programme, which provided connections with neighbouring countries and between all the regional capitals and most regional sub-centres (Rozporządzenie... 2004). The year-on-year increase in possibilities of co-financing from EU funds led to an acceleration in the development of the road network (Rosik et al. 2015). Most regional centres got direct access to a modern road network. As a result, the total length of high-speed roads was multiplied by six during the decade 2005-2015 and now exceeds $3000 \mathrm{~km}$.

\section{Results}

This section is divided into three parts. In the first part we interpret the overall (global, i.e. at the national scale) annual changes in accessibility level. The second part is dedicated to regional disparities in the change in accessibility in two successive periods: the decade of infrastructure stagnation (1995-2005) and the decade of the 'big push' to roads (2005-2015). In the last part, we investigated the effects of accessibility change on the level of territorial cohesion. In all three parts we consider the series of different $\beta$ parameters and the role of both components (transport and population).

\subsection{Overall Accessibility Changes}

During the first decade the improvement in accessibility was very limited, regardless of the $\beta$ parameter applied (Fig. 3). The situation has changed since Poland obtained access to EU funds and a series of investments began related to the EU programming and reporting periods. The huge increase in accessibility values at the end of the last EU programming period (i.e. the years 2013-2015, due to the " $n+2$ rule", according to which payments can be called up two years after the end of the programming period 


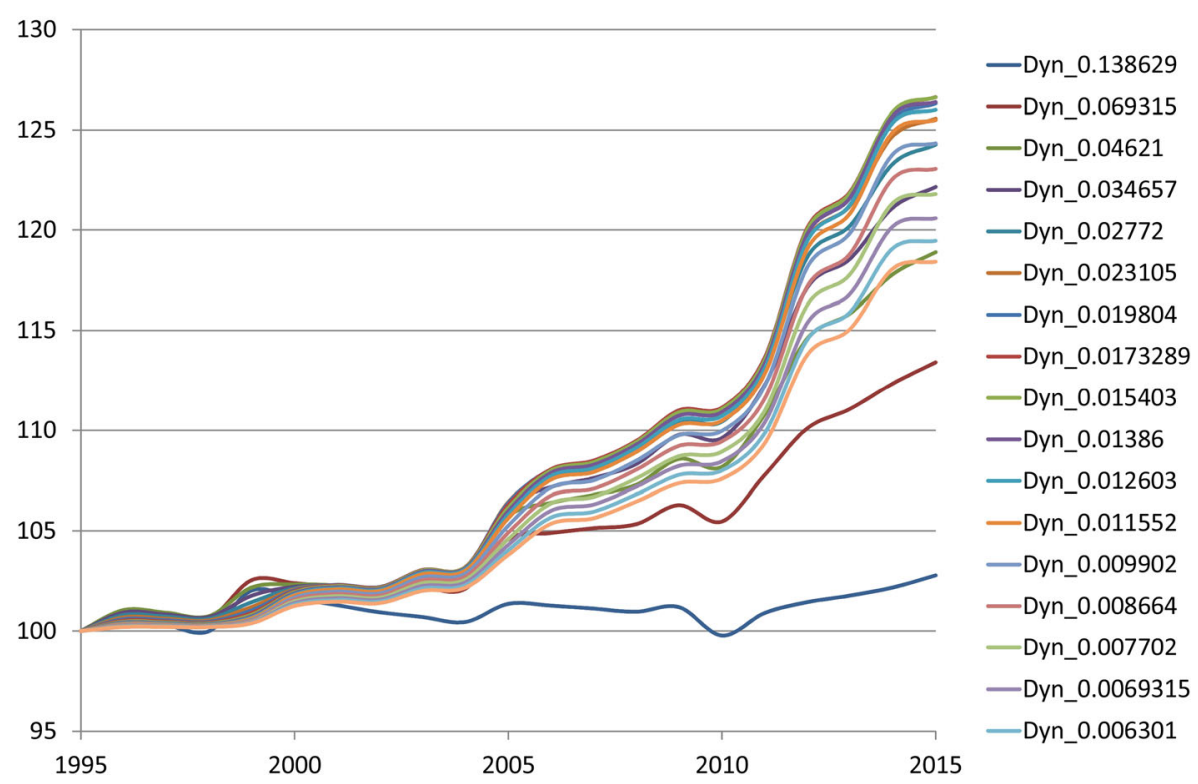

Fig. 3 Relative change of accessibility at national level (1995-2015)

during which they have been allocated, i.e. up to the end of 2015 for the programming period 2007-2013) best exemplified the process described. Moreover, several investments were encouraged by the economic and political mobilisation related to the hosting of the Euro 2012 football championships. The variation in the intensity of infrastructure investments was decisive in relation to the evolution of accessibility values, as total accessibility change was a direct output of the transport component, while the impact of the population one was very limited. The relative accessibility changes in the dynamic and population-constant variants are strongly correlated (above $0.99)$, with only one exception, that of very short trips $(\beta=0.138629)$. In the case of the latter, the population component has a greater impact due to a large share of selfpotential in the total accessibility value (Fig. 4).

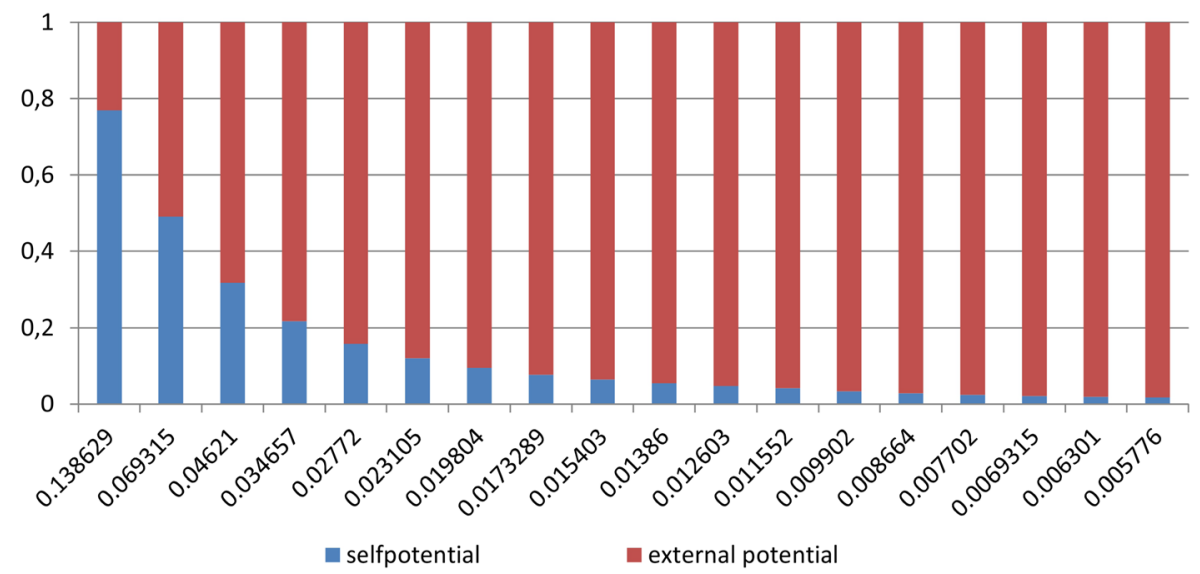

Fig. 4 Share of self-potential in the total accessibility value (national population-weighted average) 
The share of self-potential is useful in the interpretation of differences in the change in relative accessibility between different distance decay factors. The overall increase in accessibility is definitely not the highest for very short trips or for long trips, but it is for medium ones (the greatest growth in accessibility was $26.6 \%$ for $\beta=0.0173289$ ). An unchangeable transport component of self-potential limits the increase in accessibility for the shortest trips. Moreover, the accessibility gains for very short trips are limited by small spillover effects. At the other extreme, in the case of lower $\beta$ values, a high base level of accessibility prevents a further rapid increase in relative accessibility.

\subsection{Spatial Pattern of Accessibility Change}

The spatial dimension of accessibility change and the role of particular components is more nuanced, particularly, during the first decade of the period analysed. Infrastructure investments are limited and mostly located in the western and south-western part of the country. In consequence, the areas with the greatest increase in accessibility are located around the most important projects, and the spatial size of these peaks is triggered by the different scales of spatial spillover effect, larger for longer (Fig. 5) than for shorter trips (Fig. 6). ${ }^{2}$ Nevertheless, during this decade of chaotic progress in road infrastructure (1995-2005) the population component is a key driving force for the change of accessibility level in areas of population growth (Kashubia and the Warsaw agglomeration) or decline (in Eastern Poland, Middle Pomerania or the Lódzkie voivodeship in the central part of the country). Spatial spillover is a key factor in the delineation of areas affected by a given component. Gentler distance decay induces the spillover effect to reach more distantly located destinations, thus a domination of the population component is limited to the area of Warsaw (centre of the country) or Gdansk (north of the country). An interesting interplay of two nearly equivalent processes with opposite signs takes place in the Upper Silesia region where the strong depopulation of the core of the conurbation is outweighed by the improvement in infrastructure including a motorway bypassing the conurbation. In consequence this leads to the small gains in accessibility observed in this area for both long and short trips.

In the decade 2005-2015, as the process of infrastructure development accelerated, the population factor remains dominant only in the eastern fringes of the country for calculations relating to short trips. By the end of the second decade, the completion of the major transport investments led to an unprecedented level of accessibility gains in the potential core of central and southern Poland, although an increase in the accessibility level is also noted in other parts of the country. As a result, the overwhelming dominance of the infrastructure component is visible both in the core and the periphery with a spatial pattern of multiple peaks for short trips and a more balanced pattern for long trips. There are also some places where the balanced impact of both components might be the effect of relatively small, or just a lack of, both population growth and infrastructure improvement (Opolskie voivodehip, peripheral fringes of the Lubelskie and Podlaskie voivodeships). Regardless of the scale of infrastructure improvement,

\footnotetext{
${ }^{2}$ In order to save space we decided to attach only two, the most representative, sets of figures that present relative changes in potential accessibility and the role of given components. Another 3 different outcomes of analyses for diverse $\beta$ parameters are attached in supplementary material. The remaining outcomes are available on request.
} 


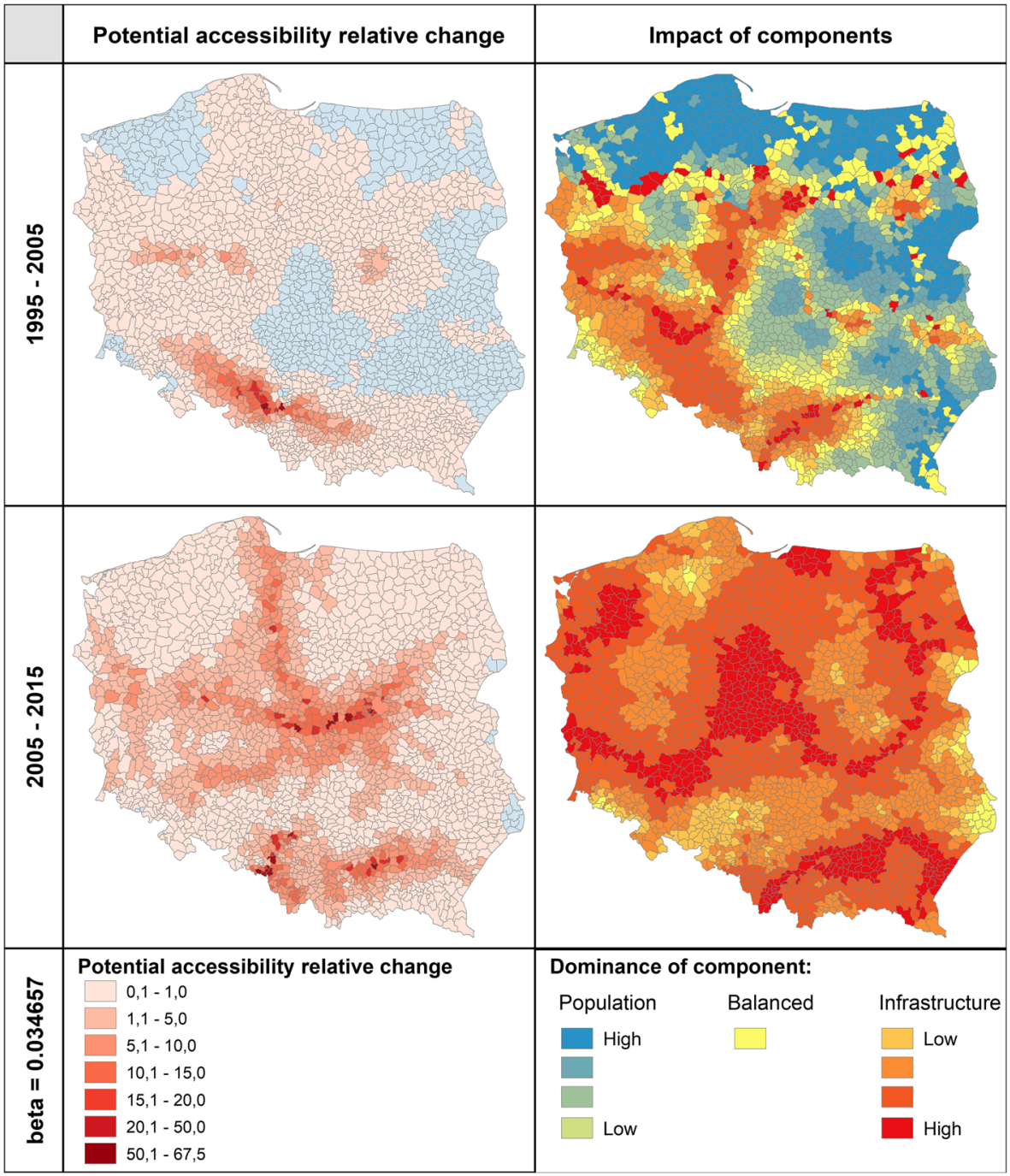

Fig. 5 Relative changes in potential accessibility and the role of the population and infrastructure components*. Short trips $(\beta=0.034657,20 \mathrm{~min}$ ). *Rc break values: +/- 0.2 (balanced); 0.2-0.5 (low); 0,5-0.8; 0.80-95 and 0.95-1.0 (high)

either small (1995-2005) or large (2005-2015), the value of $\beta$ is decisive for the evaluation of a given component: a smaller $\beta$ parameter produces larger spatial spillovers, enhancing the role of the transport component.

\subsection{Effect on the Level of Territorial Cohesion}

During the period of infrastructure stagnation (1995-2005), changes in the level of territorial cohesion are mainly induced by the population component and are heavily constrained ( $+/-2 \%$ of $\mathrm{AD}$, accessibility dispersion index, to 2005 ; Fig. 7). Nevertheless, the completion of centrally located investments at the end of this period has a very 


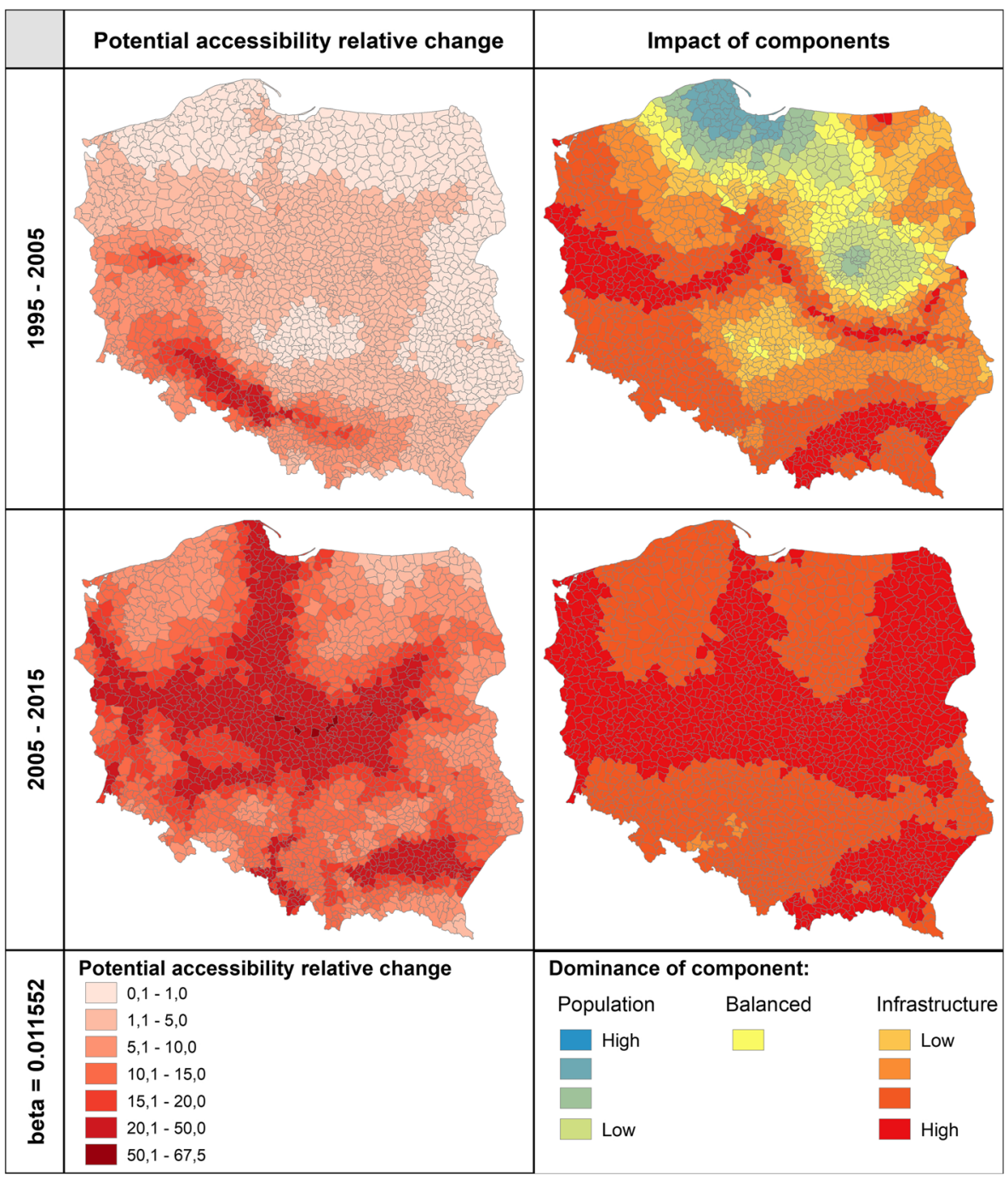

Fig. 6 Relative changes in potential accessibility and the role of the population and infrastructure components*. Long trips $(\beta=0.011552,60 \mathrm{~min})$. *Rc break values: +/- 0.2 (balanced); $0.2-0.5$ (low); 0,5-0.8; 0.80-95 and 0.95-1.0 (high)

strongly polarising effect. Moreover, an anticohesion effect is exceptionally strong when considering short and medium trips as cohesion inducing spatial spillovers do not reach more distantly located destinations. After this "polarisation peak" of the mid2000 s, the convergence process is taking place regardless of the model parameters. The big push to motorway investments at the end of the period being examined (20122015), in particular to those located on the periphery, has a clearly visible pro-cohesion effect. Moreover, the convergence of accessibility values is also an outcome of demographic change encouraging more balanced development. This is mainly due to the suburbanisation process as well as the population increase in some peripherally located areas, e.g. in the northern (Kashubia region) or southern (Podhale) part of the 


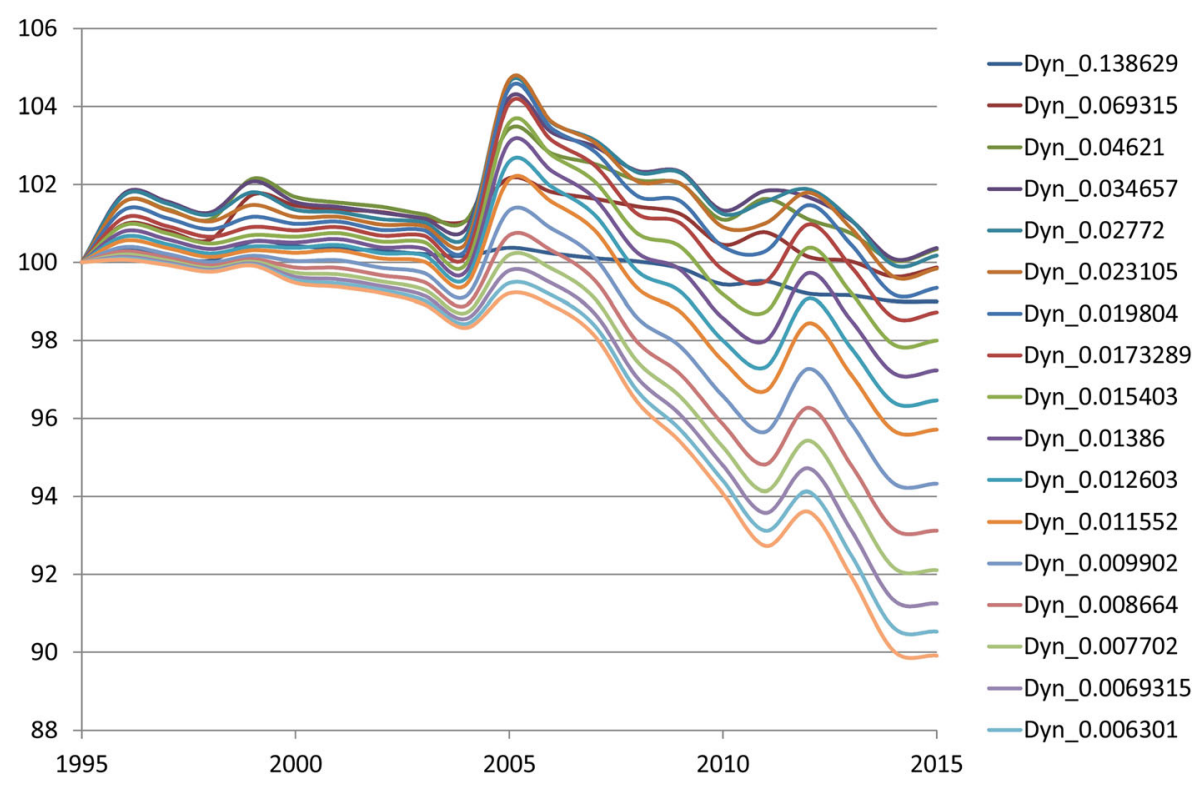

Fig. 7 Relative change of level of territorial cohesion (1995-2015)

country. However, if very long trips are taken into account, the pro-cohesion demographic effect is partially mitigated by migrations from peripheral areas to the big cities.

Therefore, the particular model parameter may affect assessment of the effect of the change in accessibility on the level of territorial cohesion and the role of particular components. In general, a reduction in the $\beta$ parameter strengthens the conclusions on the process of accessibility convergence, which is even more visible in circumstances of dominance of the infrastructure component. Importantly, the selection of a particular $\beta$ parameter may affect the most general inference results, whether we observe convergence or polarisation of accessibility.

Selection of a particular $\beta$ parameter affects the balance between the efficiency and equity of accessibility (Fig. 8). High values of the parameter (very short trips) result in a polycentric pattern of the highest accessibility values, i.e. with multiple hot-spots of accessibility and a widely spread-out periphery. The very steep distance decay provokes that changes of any, land use or infrastructure components, have very limited spatial range. In result, the observed accessibility improvement, as well as the change of territorial cohesion level are hardly noticeable. The most prevalent demographic changes (like urban sprawl) lead to a very slow sigma accessibility convergence. Moreover, high values of the $\beta$ parameter significantly limit the spatial range of spillovers, thus accessibility improvements resulting from infrastructure developments are concentrated in areas in the immediate vicinity of transport investments. Thus, very short trips are close to a "zero-sum game" both in terms of efficiency and equity, no matter if we investigate the influence of population, infrastructure or both components together. The unchangeable infrastructure component of self-potential became an issue of key importance for the results.

The increase in accessibility is more visible as the value of the $\beta$ parameter reduces. Focus on short and medium trips (i.e. 10-30 min half-life) extends the spatial range of gains from infrastructure improvements. In consequence, larger area is affected by accessibility improvement, which, in turn, causes higher increase in terms of national 


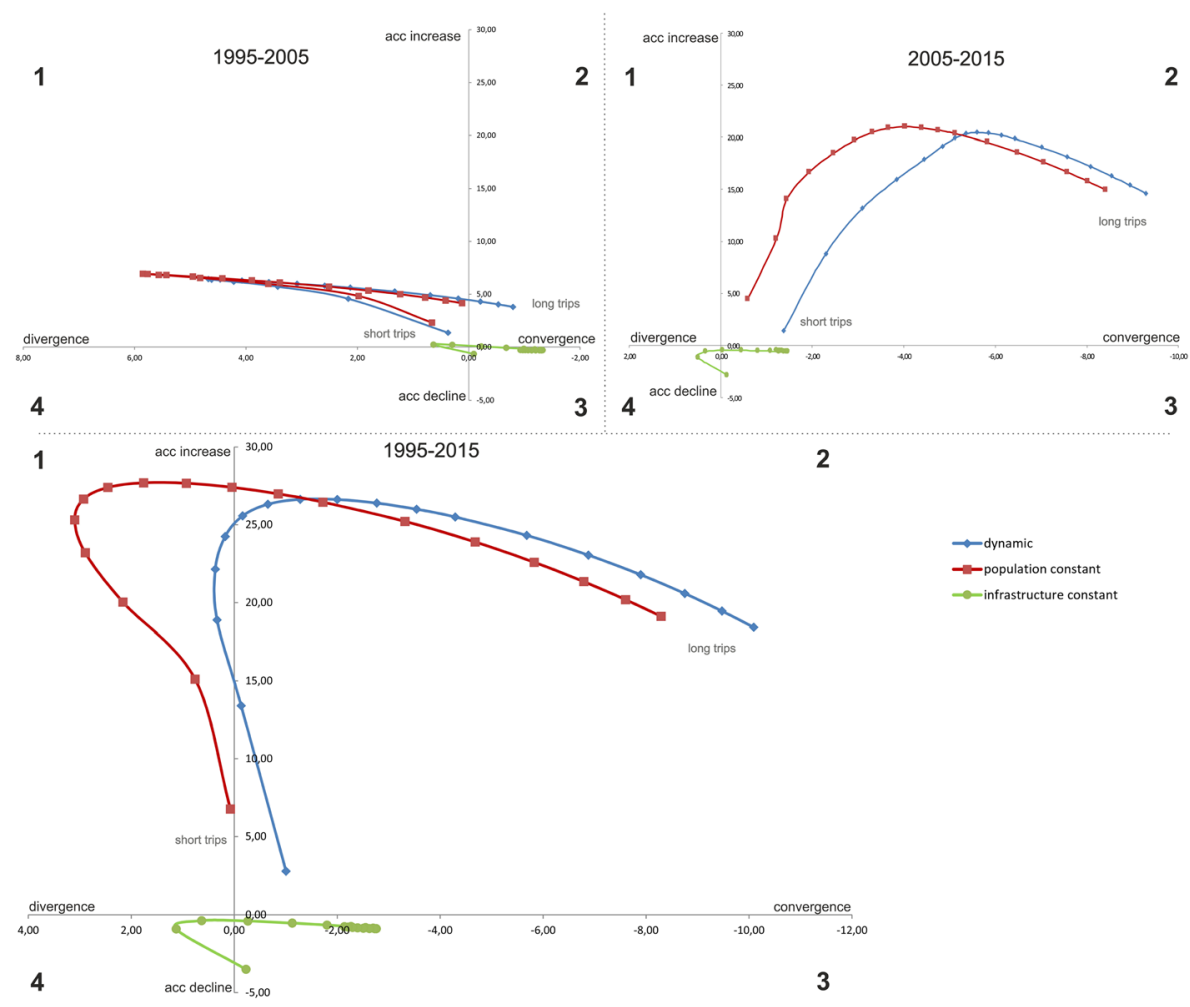

Fig. 8 The interplay between efficiency (accessibility gains) and equity (accessibility dispersion) by accessibility components and gradient of the distance decay function (relative change): 1995-2005 (upper left); b: 2005-2015 (upper right), c: 1995-2015 (bottom)

average. Nevertheless, spatial range of spillovers is still limited and does not reach the most peripheral areas. Major gains in accessibility are attributed to cities which are linked by modernised roads, while peripheral areas remain off the beaten track. Moreover, some parts of country, especially in the eastern Poland, were only slightly affected by road development programmes, as big share of the recent road investments is located in the most accessible, central and south-eastern part of the country. As a consequence, improvement of the infrastructure induces a strong polarisation even though the population component reinforces cohesion.

Further diminishing of $\beta$ values suggests greater gains in accessibility, with the maximum obtained at a value of 0.0173289 (40 min half-life). If lower values of the parameter are considered, the core of high accessibility is increasingly flat and concentrated in the densely populated central and southern part of the country while the periphery remains only at the national borders. The improvement of infrastructure leads to a wide range of spatial spillovers, the neighbourhood effect is observed even in remote regions and the acceleration of accessibility convergence is taking place.

Finally, the graph that presents the interplay between efficiency and territorial cohesion (Fig. 8) underlines the importance of the infrastructure component for the territorial cohesion effect. The curve representing the dynamic variant accurately follows the one for the infrastructure variant. The role of the population component 
is limited, even during the first decade, when the accessibility improvement resulted from infrastructure development was low, as only a limited number of transport investments was realized. Further, even though the shape of the curve of population variant is similar to the transport one, they have different turning points. In general, the population redistribution provokes the convergence of accessibility values, except the very short trips (10-15 min half-life), while the role of infrastructure is more nuanced and strongly depends on the scale of investments. In the years 1995-2005, low number of unevenly distributed investments (i.e. mostly in central and southern part of the country) strengthen polarisation of accessibility. In the second decade, transport infrastructure investments accelerate, which seems to be decisive for the process of convergence of accessibility. Surprisingly, in the circumstances of high accessibility improvement, the uneven distribution of investments has no visible impact on the level of territorial cohesion.

If one looks at the pattern of interplay between the two components over the decades, one comes to the conclusion that the period of infrastructure stagnation and slow increase in accessibility is responsible for a process of divergence in the mediumtrip category. If only the second decade is taken into account, the regional disparities would decrease regardless of the distance decay rate applied. Nevertheless, for each of the decades analysed, the highest efficiency in terms of changes in accessibility is observed in the medium trip (30-45 min. Half-life) category and the gentler is the impedance, the greater is the reduction in regional disparities.

\section{Conclusions}

Applying potential accessibility measures to the evaluation of changes in accessibility requires awareness of its methodological features which may influence the interpretation of the results obtained, or even the final values themselves. In the present paper we focus on the two main components of accessibility, transport (infrastructure) and land-use (population), and we investigate how, and to what extent, conclusions might be distorted by the selection of a given distance decay function. The analysis of the interplay between the two components facilitates the interpretation of the results as it enables one to extract the net effects of changes in the population and/or transport network. It is crucial, e.g. for ex-post evaluation of infrastructure developments, however it might also be useful for ex-ante evaluation, providing meaningful insights e.g. on how forecast population change might be reinforced or mitigated by transport re-organisation (including new investments) in order to achieve a more efficient and/or more equitable accessibility level. We conclude that the selection of a particular parameter of distance decay function has an influence on the scale of accessibility improvement. Moreover, the same change in accessibility may be interpreted as pro- or anti-cohesion, depending on the parameters of the accessibility model applied.

The population component, which dominates during the first decade, has a very limited impact on both accessibility change and territorial cohesion. In consequence, changes in levels of both accessibility and territorial cohesion are very limited during this period. At the same time, the dominance of the population component in 
accessibility change is limited to that period and refers spatially to municipalities located beyond the spatial range of spillovers that arise around completed investments. As the spatial reach of spillovers increases inversely to the value of the $\beta$ parameter (i.e. together with trip length), areas that are under the dominant influence of the population component are more limited where longer trips are concerned (cf. Figs. 5 and 6). Furthermore, larger scale infrastructure development in the second decade results in the disappearance of such types of area, and changes in accessibility in all municipalities are mostly dependent on the transport component. This conclusions are in contrast to the results presented by Condeço-Melhorado et al. (2017) and Geurs and Ritsema van Eck (2003). However, our results suggest that, the selection of a particular distance decay function may only lead to contradictory conclusions on the role of a given component in changes in accessibility during the period of stagnation of infrastructure investments and then only to a limited extent. Thus, future research is needed, involving a long-lasting accessibility monitoring in other case-study areas.

Further, we agree with the conclusion made by Condeço-Melhorado et al. (2017), that the selection of the distance decay function is irrelevant for the interpretation of causes of accessibility improvement (i.e. transport- or population-related). Of course, the scale of change in accessibility varies, mostly due to the divergent role of selfpotential and the differentiated spatial range of spillovers, but no one has doubts when it comes to distinguishing periods of more or less intense change in accessibility.

Nevertheless, the use of model parameters has a decisive impact when an evaluation of accessibility change covers the impact on the level of territorial cohesion. The application of higher values of the $\beta$ parameter (short trips) suggests conclusions about the existence of the polarisation process at a low scale of accessibility change. The decrease of a parameter (medium-length trips) gives an output with higher levels of improvement in accessibility, but also provides arguments for its limited effect in promoting cohesion. A further process of decrease in this parameter results in a slight decrease in accessibility and, simultaneously, a more visible convergence of accessibility and a reduction in regional disparities. However, in the extreme case of flat decay, distance does not matter anymore, so all settings of accessibility components result in an egalitarian space.

The above-mentioned conclusions refer directly to the recently observed change in levels of accessibility and its spatial pattern in Poland, and to the second of the decades investigated in particular. In the upcoming stages of infrastructure development, a further process of convergence of accessibility will be a natural consequence, irrespective of the model parameters applied. We argue that the process of divergence in accessibility values is more the exception than the rule and as a phenomenon takes place only at the initial stage of infrastructure development, while in the long term the potential accessibility dispersion index should decrease, regardless of the value of the $\beta$ parameter. Nevertheless, if the process of infrastructure development slows down or stops, the population component might be dominant over the infrastructure one. In that case, the strengthening of territorial cohesion will be related to the deconcentration of population processes and suburban development (including urban sprawl), while migration from peripheral to central regions, urbanisation, and re-urbanisation in general will strengthen polarisation and lead to a sigma divergence in accessibility .

The paper indicates that the spatial differentiation of the dominance of transport or land-use components depends on many circumstances like the time span, distance 
decay and location of existing and/or newly built infrastructure. We focus on the impact of distance decay parameters on the interpretation of the results of the analysis of accessibility change. Future research should focus on international comparisons, especially between mono- and polycentric countries with different settlement structures, including a long time span (preferably several decades) in order to capture subsequent stages of infrastructure development and long-lasting demographic processes.

Acknowledgements This research was funded by the Polish National Science Centre allocated on the basis of the decision no. DEC -2016/21/B/HS4/01578. Scripts used to calculate potential accessibility were developed within the project funded by the Polish National Science Centre allocated on the basis of the decision no. DEC-2013/09/D/HS4/02679.

Open Access This article is distributed under the terms of the Creative Commons Attribution 4.0 International License (http://creativecommons.org/licenses/by/4.0/), which permits unrestricted use, distribution, and reproduction in any medium, provided you give appropriate credit to the original author(s) and the source, provide a link to the Creative Commons license, and indicate if changes were made.

\section{References}

Aschauer DA (1989) Is public expenditure productive? J Monet Econ 23:177-200. https://doi.org/10.1016 /0304-3932(89)90047-0

Axhausen KW, Froelich P, Tschopp M (2011) Changes in Swiss accessibility since 1850. Res Transp Econ 31: 72-80. https://doi.org/10.1016/j.retrec.2010.11.010

Barro RJ, Sala-i-Martin X (1992) Convergence. J Polit Econ 100:223-251. https://doi.org/10.1086/261816

CEC (Commission of the European Communities) (2004) A new partnership for cohesion: convergence competitiveness cooperation. Third report on economic and social cohesion. Office for Official Publications of the European Communities, Brussels

CEC (Commission of the European Communities) (2007) Growing regions, growing Europe. Fourth report on economic and social cohesion. Office for Official Publications of the European Communities, Luxembourg

Condeço-Melhorado A, Christidis P (2017) Road accessibility in border regions: a joint approach. Netw Spat Econ. https://doi.org/10.1007/s11067-017-9362-1

Condeço-Melhorado A, Gutiérrez J, García-Palomares JC (2011a) Spatial impacts of road pricing: accessibility, regional spillovers and territorial cohesion. Transp Res A Policy Pract 45(3):185-203. https://doi.org/10.1016/j.tra.2010.12.003

Condeço-Melhorado A, Martín JC, Gutiérrez J (2011b) Regional spillovers of transport infrastructure investment: a territorial cohesion analysis. Eur J Transp Infrastruct Res 11:389-404

Condeço-Melhorado AM, Gutiérrez J, García-Palomares JC (2013) Influence of distance decay on the measurement of market potential and the spillover effect of transport infrastructure. Geofocus 13:22-47

Condeço-Melhorado A, Zofío JL, Christidis P (2017) Drivers of changes in Spainish accessibility for the 1960-2010 period. Eur Transp Res Rev. https://doi.org/10.1007/s12544-017-0229-9

Erath A, Löchl M, Axhausen KW (2009) Graph-theoretical analysis of the Swiss road and railway networks over time. Netw Spat Econ 9:379-400. https://doi.org/10.1007/s11067-008-9074-7

Fayard A, Meunier D, Quinet E (2012) Motorway provision and Management in France: analyses and policy issues. Netw Spat Econ 12:299-319. https://doi.org/10.1007/s11067-009-9122-y

Fihel A, Anacka M, Kaczmarczyk P, Stefańska R (2011) Recent trends in international migration in Poland: the 2011 SOPEMI report

Geurs KT, Ritsema van Eck JR (2001) Accessibility measures: review and applications. National Institute of Public Health and the Environment, Bilthoven

Geurs KT, Ritsema van Eck JR (2003) Evaluation of accessibility impacts of land-use scenarios: the implications of job competition, land-use, and infrastructure developments for the Netherlands. Environ Plann B Plann Des 30:69-87. https://doi.org/10.1068/b12940 
Geurs KT, van Wee B (2004) Accessibility evaluation of land-use and transport strategies: review and research directions. J Transp Geogr 12:127-140. https://doi.org/10.1016/j.jtrangeo.2003.10.005

Geurs KT, Ponce Dentinho T, Patuelli R (2016) Accessibility, equity and efficiency. In: Geurs KT, Ponce Dentinho T, Patuelli R (eds) Accessibility, equity and efficiency. Challenges for transport and public services. Edward Elgar Publishing, Cheltenham, pp 3-8. https://doi.org/10.4337/9781784717896.00007

Handy SL, Niemeier DA (1997) Measuring accessibility: an exploration of issues and alternatives. Environ Plan A 29:1175-1194. https://doi.org/10.1068/a291175

Hansen WG (1959) How Accessibility Shapes Land Use. J Am Inst Plann 25(2):73-76

Haynes R, Lovett A, Sünnenberg G (2003) Potential accessibility, travel time, and consumer choice: geographical variations in general medical practice registrations in eastern England. Environ Plan A 35: 1733-1750. https://doi.org/10.1068/a35165

Holl A (2004) Manufacturing location and impacts of road transport infrastructure: empirical evidence from Spain. Reg Sci Urban Econ 34:341-363. https://doi.org/10.1016/S0166-0462(03)00059-0

Holl A (2007) Twenty years of accessibility improvements. The case of the Spanish motorway building programme. J Transp Geogr 15:286-297. https://doi.org/10.1016/j.jtrangeo.2006.09.003

Holl A, Mariotti I (2017) The geography of logistics firm location: the role of accessibility. Netw Spat Econ:125. https://doi.org/10.1007/s11067-017-9347-0

Jiang X, Zhang L, Xiong C, Wang R (2016) Transportation and regional economic development: analysis of spatial spillovers in China provincial regions. Netw Spat Econ 16:769-790. https://doi.org/10.1007 /s11067-015-9298-2

Jiménez JL, Perdiguero J (2011) Does accessibility affect retail prices and competition? An empirical application. Netw Spat Econ 11:677-699. https://doi.org/10.1007/s11067-010-9144-5

Kaczmarczyk P, Dąbrowski P, Fihel A, Stefańska R (2014) Recent trends in international migration in Poland: the 2012 SOPEMI report

Komornicki T (2007) Polish transport infrastructure - challenges for spatial cohesion. Euro Spat Res Policy 14: 31-52

Kotavaara O, Antikainen H, Rusanen J (2011) Population change and accessibility by road and rail networks: GIS and statistical approach to Finland 1970-2007. J Transp Geogr 19:926-935. https://doi.org/10.1016/j.jtrangeo.2010.10.013

Kwan M-P (1998) Space-time and integral measures of individual accessibility: a comparative analysis using a point-based framework. Geogr Anal 30:191-216. https://doi.org/10.1111/j.1538-4632.1998.tb00396.x

Levinson D, Xie F, Oca NM (2012) Forecasting and evaluating network growth. Netw Spat Econ 12:239-262. https://doi.org/10.1007/s11067-009-9113-Z

López E, Gutiérrez J, Gómez G (2008) Measuring regional cohesion effects of large-scale transport infrastructure investments: an accessibility approach. Eur Plan Stud 16:277-301. https://doi.org/10.1080 /09654310701814629

Martens K, Golub A, Robinson G (2012) A justice-theoretic approach to the distribution of transportation benefits: implications for transportation planning practice in the United States. Transp Res A Policy Pract 46:684-695. https://doi.org/10.1016/j.tra.2012.01.004

Moya-Gómez B, García-Palomares JC (2017) The impacts of congestion on automobile accessibility. What happens in large European cities? J Transp Geogr 62:148-159. https://doi.org/10.1016/j. jtrangeo.2017.05.014

Moya-Gómez B, Salas-Olmedo MH, García-Palomares JC, Gutiérrez J (2017) Dynamic accessibility using big data: the role of the changing conditions of network congestion and destination attractiveness. Netw Spat Econ:1-18. https://doi.org/10.1007/s11067-017-9348-z

Ortega E, López E, Monzón A (2012) Territorial cohesion impacts of high-speed rail at different planning levels. J Transp Geogr 24:130-141. https://doi.org/10.1016/j.jtrangeo.2011.10.008

Östh J, Reggiani A, Galiazzo G (2014) Novel methods for the estimation of cost-distance decay in potential accessibility models. In: Condeço-Melhorado A, Reggiani A, Gutiérrez J (eds) Accessibility and spatial interaction. Edward Elgar, Cheltenham, pp 15-37

Pereira AM, Roca-Sagalés O (2003) Spillover effects of public capital formation: evidence from the Spanish regions. J Urban Econ 53:238-256. https://doi.org/10.1016/S0094-1190(02)00517-X

Reggiani A, Martín JC (2011) Guest editorial: new Frontiers in accessibility modelling: an introduction. Netw Spat Econ 11:577-580. https://doi.org/10.1007/s11067-011-9155-x

Reggiani A, Bucci P, Russo G (2011) Accessibility and impedance forms: empirical applications to the German commuting network. Int Reg Sci Rev 34:230-252. https://doi.org/10.1177/0160017610387296

Rosik P, Stępniak M (2015) Monitoring of changes in road potential accessibility at municipality level in Poland, 1995-2015. Geogr Pol 88:607-620. https://doi.org/10.7163/GPol.0036 
Rosik P, Stepniak M, Komornicki T (2015) The decade of the big push to roads in Poland: impact on improvement in accessibility and territorial cohesion from a policy perspective. Transp Policy 37:134 146. https://doi.org/10.1016/j.tranpol.2014.10.007

Rozporządzenie... (2004) Rozporządzenie Rady Ministrów z dnia 15 maja 2004 r. w sprawie sieci autostrad i dróg ekspresowych (Dz.U. Nr 128, poz. 1334 z późń. zm.)

Salas-Olmedo MH, Condeço-Melhorado A, Gutiérrez J (2014) Border effect and market potential: the case of the European Union. In: Condeço-Melhorado A, Reggiani A, Gutiérrez J (eds) Accessibility and spatial interaction. Edward Elgar Publishing, Cheltenham, pp 133-155

Salas-Olmedo MH, García P, Gutiérrez J (2015) Accessibility and transport infrastructure improvement assessment: the role of borders and multilateral resistance. Transp Res A Policy Pract 82:110-129. https://doi.org/10.1016/j.tra.2015.09.009

Śleszyński P (2005) Differences in the size of the population revealed by the 2002 National Census (in Polish: Różnice liczby ludności ujawnione w Narodowym Spisie Powszechnym 2002). Prz Geogr 77:193-212

Śleszyński P (2011) Oszacowanie rzeczywistej liczby ludności gmin województwa mazowieckiego z wykorzystaniem danych ZUS. Studia Demogr 2:35-58

Śleszyński P (2013) Demographic change in the functional urban areas in Poland, 2000-2010. Geogr Pol 86: 169-170. https://doi.org/10.7163/GPol.2013.16

Solé-Ribalta A, Gómez S, Arenas A (2017) Decongestion of urban areas with hotspot pricing. Netw Spat Econ:1-18. https://doi.org/10.1007/s11067-017-9349-y

Spiekermann K, Neubauer J (2002) European accessibility and peripherality: concepts, models and indicators. Nordregio Working Paper. Stockholm

Spiekermann K, Wegener M, Květoň V, et al (2013) TRACC transport accessibility at regional/local scale and patterns in Europe. Final Report. ESPON Applied Research

Stelder D (2013) Regional accessibility in Europe : the impact of road infrastructure 1957-2012. 1-25. doi: https://doi.org/10.1080/00343404.2014.952721

Stepniak M, Rosik P (2013) Accessibility improvement, territorial cohesion and spillovers: a multidimensional evaluation of two motorway sections in Poland. J Transp Geogr 31:154-163. https://doi.org/10.1016/j. jtrangeo.2013.06.017

Stępniak M, Rosik P (2016) From improvement in accessibility to the impact on territorial cohesion: the spatial approach. J Transp Land Use 9:1-13. https://doi.org/10.5198/jtlu.2015.570

Taylor Z (2006) The transport system of Poland in a period of transition. In: Degórski M (ed) Natural and human environment of Poland. A geographical overview. IGiPZ PAN, Warsaw, pp 275-296

Thomopoulos N, Grant-Muller S, Tight MR (2009) Incorporating equity considerations in transport infrastructure evaluation: current practice and a proposed methodology. Eval Program Plann 32:351-359. https://doi.org/10.1016/j.evalprogplan.2009.06.013

van Wee B, Geurs KT (2011) Discussing equity and social exclusion in accessibility evaluations. Eur J Transp Infrastruct Res 11:350-367

Vickerman R, Spiekermann K, Wegener M (1999) Accessibility and economic development in Europe. Reg Stud 33:1-15. https://doi.org/10.1080/00343409950118878

Wiśniewski R, Szejgiec-Kolenda B, Śleszyński P (2016) Population changes and population ageing in Poland between 1960 and 2011. Geogr Pol 89(2):259-265. https://doi.org/10.7163/GPol.0056

Xie F, Levinson D (2007) Measuring the structure of road networks. Geogr Anal 39:336-356. https://doi.org/10.1111/j.1538-4632.2007.00707.x

Yu N, de Jong M, Storm S, Mi J (2013) Spatial spillover effects of transport infrastructure: evidence from Chinese regions. J Transp Geogr 28:56-66. https://doi.org/10.1016/j.jtrangeo.2012.10.009

Zborowski A, Soja M, Łobodzińska A (2012) Population trends in Polish cities - stagnation, depopulation or shrinkage? Pr Geogr 130:7-28 